centrations necessary to maintain peripheral tissue triiodothyronine concentrations may therefore suppress the release of thyroid stimulating hormone. Clearly thyroid stimulating hormone alone cannot be used to monitor the adequacy of replacement treatment in primary hypothyroidism, and so the dosage of thyroxine should be adjusted so that the free triiodothyronine concentration is within the normal range.

In patients with thyroid carcinoma suppression of thyroid stimulating hormone by thyroxine in doses of up to $400 \mu \mathrm{g}$ daily is an important part of management; our results indicate that lower doses would be adequate to achieve such suppression. Assays of thyroid stimulating hormone concentration with a high sensitivity would show that thyroxine treatment suppresses basal thyroid stimulating hormone concentrations; such assays should render thyrotrophin releasing hormone tests unnecessary in these patients.

1 Pearce CJ, Himsworth RJ. Total and free thyroid hormone concentrations in patients receiving maintenance replacement treatment with thyroxine. $\mathrm{Br} M$ ed $\mathcal{F}$

2 Larsen PR. Thyroid-pituitary interaction: feedback regulation of thyrotrophin .

(Accepted 8 November 1984)

Wessex Regional Department of Nuclear Medicine, Southampton General Hospital, Southampton SO9 4XY

R J MARDELL, BSC, senior biochemist

Department of Chemical Pathology, Milton Keynes District General Hospital, Milton Keynes MK6 5LD

T R GAMLEN, PHD, MRCP, chemical pathologist

M R J WINTON, FIMLS, chief medical laboratory scientific officer

Correspondence to: $\mathbf{M r} \mathbf{R}$ J Mardell.

\section{Factors contributing to delay in diagnosis of testicular tumours}

Close to $80 \%$ of patients who have malignant teratoma with no detectable metastases remain free from disease after orchidectomy alone $\mathrm{e}^{1-3}$; in the remainder relapse is detected sufficiently early for most to be cured by chemotherapy. Some doctors, however, remain unaware that a delay in diagnosing testicular tumours affects the chance of long term cure and whether and how much chemotherapy is needed.

In this unit the average delay from the first symptom to diagnosis was found to have been two months in patients who remained free from disease after one year of follow up." In those patients with metastases at diagnosis or after a period of surveillance who subsequently died of drug resistant disease the average delay in diagnosis was seven months, whereas in those with metastases cured by chemotherapy it was four months. Ninety three per cent of patients with less than one month's delay in diagnosis had no clinically obvious metastases at presentation whereas half of those with more than six months' delay had clinically palpable metastases. I have reviewed the histories of patients with prolonged delay in diagnosis of testicular tumours reported on previously ${ }^{5}$ and present two illustrative histories to highlight the need to encourage early diagnosis.

\section{Case reports}

In 24 of 52 patients with teratoma and five of 12 patients with seminoma the delay in diagnosis was over six months. The table summarises the symptoms at presentation and the stage.in the diagnostic process that produced the longest delay.

Case 1-A 26 year old man had had a painful, swollen testicle of acute onset and been treated with antibiotics two years before diagnosis. Though his general practitioner was aware that the swelling persisted the testicle was not re-examined at subsequent visits. Because the patient was shy about being examined he did not seek advice even though he noticed that the swelling had increased. One month before diagnosis he developed abdominal pain, and he was finally admitted to hospital after further delay with obstructed jaundice and vast abdominal, testicular, and lung masses. After chemotherapy and extensive thoracoabdominal surgery he remained free from disease for four years, though the combined effects of chemo- therapy and radiotherapy needed to treat a metastasis of the brain caused near total alopecia.

Case 2-A man aged 29 had been examined when he was 20 but had not been given any advice about his undescended testicle. Three years before diagnosis he saw an orthopaedic surgeon for backache attributed to driving a car. The pain fluctuated but persisted, and twice he was admitted to hospital as an emergency because of severe exacerbations. The pain was thought to be renal in origin, but results of intravenous pyelography were normal (although on review lateral displacement of the left kidney was evident). A nodule

Symptoms present in untreated patients with more than six months' delay from first symptoms to first treatment

\begin{tabular}{lccc}
\hline & \multicolumn{3}{c}{ Longest period of delay } \\
\cline { 2 - 4 } & Patient & $\begin{array}{c}\text { General } \\
\text { practitioner }\end{array}$ & Specialist \\
\hline Gynaecomastia & & 3 & 1 \\
Backache or abdominal pain, or both & 8 & 5 & 4 \\
$\begin{array}{l}\text { Painless nodule or swelling } \\
\text { Post-traumatic or postinflammatory swelling }\end{array}$ & 1 & 1 & 1 \\
Lost on waiting list & 1 & & 1 \\
\hline Undescended testicle & 10 & 9 & 9 \\
\hline Total* & &
\end{tabular}

'Excludes one patient with eight months' delay equally divided between patient, general practitioner, surgeon, and radiotherapist who was lost for two months on

noted in his right testicle was not thought to be important, but a year later, when a further opinion was sought from a urological surgeon about his renal pain, it was found to be a small malignant teratoma. His backache resolved within 48 hours after the start of treatment and did not recur.

\section{Comment}

Diagnosis of testicular tumours is not always easy, and most delays in diagnosis occur in patients undergoing investigation of symptoms that are subsequently shown to have been caused by metastases. Patients' embarrassment in seeking help is also a factor. This report emphasises the importance of careful palpation of the testis in young men with symptoms of indeterminate origin, and also that some doctors are unaware that an important minority of testicular tumours can present either as small nodules in the testis without gross swelling or as a painful testis mimicking epididymo-orchitis.

1 Peckham MJ, Barrett A, Horwich A, Hendry WF. Orchidectomy alone in testicular stage 1 non-seminomatous germ cell tumours. Br $\mathcal{\text { Urol }}$ Uro83;55:754-9.

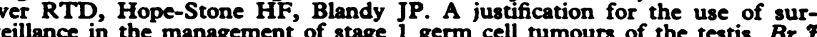
vellance in the man $1983 ; 55: 760-3$.

3 Read G, Johnson RJ, Wilkinson PM, Eddlestone B. Prospective study of follow up alone in stage 1 teratoma of the testis. Br Med $\mathcal{F} 1983 ; 287: 1503-5$.

4 Oliver RTD, Read G, Jones WG, Williams CJH, Peckham MJ. Justification for a policy of surveillance in the management of stage 1 testicular teratoma. In: Denis L, Murphy GP, Prout GR, Schroder F, eds. Controlled clinical trials in urologic oncology. New York: Raven Press, 1984:73-8.

5 Oliver RTD, Blandy JP, Hendry WF, Pryor JP, Williams JP, Hope-Stone HF.

Evaluation of radiotherapy and/or surgico-pathological staging after chemotherapy in

(Accepted 8 November 1984)

Department of Urology, The London Hospital, Whitechapel, London E1 1BB

R T D OLIVER, MD, FRCP, reader in medical oncology

\section{Obstructive jaundice caused by corrosive injury to the duodenum}

I report an unusual case in which ingestion of mineral acid caused extensive duodenal injury, resulting in obstructive jaundice presumed to be due to fibrosis of the duodenal papilla.

\section{Case report}

A 66 year old man was admitted six hours after ingesting hydrochloric acid solution with the intention of committing suicide. He had lost his job (his family's main source of income) and had consequently become depressed. 
He had drunk about $250 \mathrm{ml}$ of concentrated hydrochloric acid ( $32 \% \mathrm{w} / \mathrm{v}$, $8 \mathrm{~N}$, pH 0.9) used for cleaning toilet bowls. He had acid burns on his lips and oral mucosa and mild tenderness in the epigastrium but no other abnormal physical signs.

He was given oral antacids and was fed intravenously. Barium meal examination five days later showed that the oesophagus and proximal part of the stomach were normal, but the distal part and the prepyloric antrum were narrowed and irregular; the duodenum was normal. Endoscopy showed a normal oesophagus and mild inflammation of the proximal part of the stomach. The mucosa of the distal part and antrum showed severe necrosis and ulceration. Narrowing of the pyloric canal prevented inspection of the duodenum.

A psychiatrist diagnosed reactive depression and arranged for a social worker to help ease the family's financial problem. On discharge the patien was well and eating normally.

He was readmitted seven weeks later having vomited undigested food and passed pale stools and dark urine for four days. He looked ill, dehydrated, and jaundiced and had a dilated stomach with a succussion splash. Biochemical investigations confirmed obstructive jaundice, and barium meal examination and gastroscopy showed complete pyloric stenosis. Ultrasound scanning of the abdomen showed a dilated extrahepatic biliary system down to the ampulla of Vater but no other abnormalities; the pancreas was normal.

The dehydration and clotting disorders were corrected, and intravenous feeding was begun. Because of deepening jaundice and general deterioration laparotomy was done. The prepyloric antrum and duodenum down to the duodenojejunal flexure were considerably thickened and contracted, and the gall bladder and common bile duct were dilated. Palpation of the head

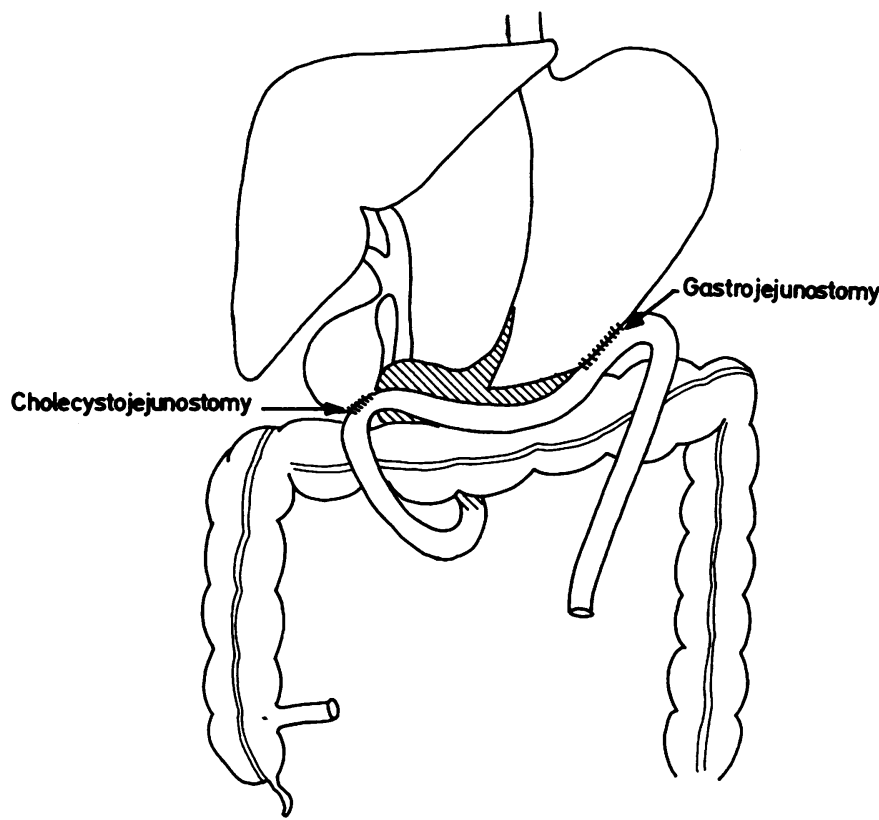

Gastrojejunostomy and cholecystojejunostomy created to bypass obstructed stomach and common bile duct. Hatched area shows extent of damage caused by ingested acid to stomach and duodenum.

of the pancreas was normal. A duodenotomy showed that the wall of the duodenum was thickened, and its lumen, which was almost obliterated contained no bile. The mucosa was inflamed and ulcerated, and the duodenal papillas were unidentifiable. A full thickness biopsy specimen of the duodenum was taken and the duodenotomy closed. A loop of jejunum was sutured to the gall bladder and stomach to create a cholecystojejunostomy and a gastrojejunostomy, bypassing the head of the pancreas and the duodenum (figure). Histological examination of the duodenal biopsy specimen showed ulceration of the mucosa, round cell infiltration, and extensive fibrosis of the duodenal wall.

He recovered completely, the jaundice cleared, and he gained weight with a normal diet. Computed tomograms of his abdomen three and six months later showed no evidence of tumour in the biliary tree or pancreas.

\section{Comment}

Clinically important corrosive injury to the upper gastrointestinal tract after ingestion of mineral acid occurs most commonly in the prepyloric antrum and sometimes in the oesophagus. ${ }^{1}$ Damage has also been reported in the proximal duodenum and the ileum in cases of severe ingestion. ${ }^{2} 3$

The cause of obstructive jaundice in this patient was thought to be either a coexisting lesion in the biliary tree or pancreas, such as stones or a tumour, or the result of duodenal injury caused by ingestion of acid. A lesion was unlikely because of the lack of evidence at laparotomy and the negative results of computed tomography. Thus it appears that if severe fibrosis in the duodenal wall spreads into the papillary area complete obstruction of the common bile duct may occur, leading to obstructive jaundice.

1 Di-Costanzo J, Cano N, Martin J, Noirclerc $M$. Surgical approach to corrosive injuries of the stomach. Br $₹$ Surg $1981 ; 68: 879-81$

2 Herrington JL. Stenosis of the gastric antrum and proximal duodenum resulting from the ingestion of a corrosive agent. Am $\mathcal{Y}$ Surg 1964;107:580.

3 Maul KI, Scher LA, Greenfield LJ. Surgical implications of acid ingestion. Surg Gynecol Obstet 1979;148:895-8.

(Accepted 15 November 1984)

Department of Surgery, Ealing Hospital, Middlesex UB1 3HW

DAVID P SELLU, CHM, FRCS, registrar

\section{Loss of form in young athletes due to viral infection}

Many athletes experience sudden and unexplained deterioration in performance in training or competition. This is often attributed to overtraining or psychological factors, but a medical illness may cause a temporary loss of form in a previously fit athlete. In the past year I have seen 12 athletes complaining of loss of form with no features suggesting an underlying medical cause. No medical abnormality was found in eight of them, though four were undergoing the stress of academic examinations. The four others showed evidence of a recent viral infection and are reported on here.

\section{Case reports}

Case 1-A 15 year old middle distance runner complained of loss of stamina and inability to manage his normal training schedule. His competition performance had also deteriorated. The problem had been preceded by a mild infection of the upper respiratory tract and a sore throat not serious enough for him to have consulted a doctor. Examination showed several small supraclavicular lymph nodes. Atypical mononuclear cells were visible in a blood film, and a screening test for infectious mononucleosis (Monospot) gave positive results. Training was temporarily reduced, and he had regained his form after four months.

Case 2-An 18 year old cross country runner complained of two months of malaise, tiredness, and difficulty in training. She had not had any upper respiratory tract symptoms. Examination gave normal results. Estimation of viral titres showed a considerable increase in Coxsackie B2 (1/512), indicating recent infection. After a short recovery period she regained her form over three months.

Case 3-An 18 year old cross country runner presented with loss of stamina, being unable to maintain his former training schedule. He had had no recent symptoms of the upper respiratory tract. Physical examination gave negative results, but he had a raised aspartate transaminase activity of 57 IU/1 (normal range 12-42), which suggested mild hepatitis. A Monospot test gave positive results, indicating recent infectious mononucleosis. Six months later he was still complaining of tiredness and aching legs and had not been able to repeat previous performances.

Case 4-A 20 year old international sprinter had had an infection of the upper respiratory tract two months previously. She had subsequently felt weak and dizzy during training and had been unable to maintain her former training capacity. Examination gave negative results. Measurement of viral titres showed a pronounced increase in Coxsackie B3 (1/256), indicating recent infection. Her loss of form persisted throughout the track season.

\section{Comment}

Two of these highly trained athletes had had no prodromal symptoms, and two had had minor symptoms of the upper respiratory tract. All had evidence of recent viral infections as shown by increased titres of antibodies against Coxsackie B or Epstein-Barr virus, and one had morphologically abnormal white blood cells suggesting recent viral infection. ${ }^{1}$

Viral infections are blamed for many minor illnesses. They may be subclinical and may give rise to symptoms beyond the acute infective phase. This post-viral syndrome produces various physical abnormalities, including excessive intracellular acidosis of skeletal muscles and persisting abnormal function of $T$ cells. ${ }^{2}{ }^{3}$ Pether 